\title{
PENERAPAN METODE FUZZY TIME SERIES UNTUK PREDIKSI PENJUALAN BERBASIS WEB PADA CV. AGVA KOTA PASURUAN
}

\author{
Andrian Irfie Hamdani, Yosep Agus Pranoto, Nurlaily Vendyansyah \\ Program Studi Teknik Informatika S1, Fakultas Teknologi Industri \\ Institut Teknologi Nasional Malang, Jalan Raya Karanglo km 2 Malang, Indonesia \\ andrianspm@gmail.com
}

\begin{abstract}
ABSTRAK
Cv.AGVA kota pasuruan merupakan toko yang menjual bermacam-macam alat drumband. Cv.AGVA menyediakan alat drumband mulai dari senar drum HTS, senar drum, marching bell, bass, terompet, dan lainlain Pada proses pendataan data penjualan Cv.AGVA kota pasuruan masih menggunakan cara lama yaitu dengan memasukkannya ke dalam buku nota. Karena pada toko belum ada sistem yang membantu untuk memprediksi penjualan maka pemilik toko kesulitan untuk menentukan stok barang yang akan disediakan.

Pada penelitian yang dikembangkan ini peneliti menggunakan metode fuzzy time series untuk melakukan.prediksi penjualan alat drumband menggunakan data histori penjualan Cv.AGVA kota pasuruan. Proses yang dilakukan dalam penelitian ini adalah yang pertama mengambil data historis penjualan marching bell mulai dari januari 2016 - desember 2018, kemudian mencari jumlah interval dan Panjang interval didapat hasil 33 jumlah interval dan 1 panjang interval. Kemudian melakukan proses fuzzifikasi pada data histori. Lalu menentukan fuzzy logical relationship dan menentukan fuzzy logical relationship grup. Langkah terakhir adalah melakukan proses prediksi atau defuzzifikasi menggunakan fuzzy logical relationship grup sebagai acuan.

Hasil perhitungan akurasi keakuratan metode Fuzzy Time Series berdasarkan data penjualan dari bulan Januari 2016 sampai Desember 2018. Baik melalui simulasi program dan manual. Nilai akurasi keakuratan sebesar berapa 2,28\%. Serta aplikasi menyediakan informasi tentang hasil penjualan setiap barang. Dengan adanya aplikasi diharapkan pengguna dapat meminimalisir penumpukan stok barang setiap bulannya.
\end{abstract}

Kata kunci : Prediksi, Penjualan, Fuzzy Time Series, Web

\section{PENDAHULUAN}

Cv.AGVA kota pasuruan merupakan salah satu toko yang menyediakan berbagai alat drumband. Penjualan Setiap bulannya mengalami naik turun dikarenakan permintaan konsumen. Makin tinggi permintaan konsumen, makin tinggi pula penjualan yang dilakukan oleh toko tersebut. Ini yang mengakibatkan persediaan menjadi tidak dinamis dan ini mempengaruhi perhitungan laba atau rugi toko.

Saat ini pengarsipan data penjualan dan pembelian Cv.AGVA masih dilakukan secara manual dengan cara dituliskan dalam buku arsip, yang cukup memakan waktu dalam penulisan juga menjadi kendala dalam perhitungan laba dan rugi toko Cv.AGVA. Selain itu penumpukan stok dikarenakan tidak tahu untung atau tidaknya pada bulan kemarin juga menjadi kendala lainnya. Jika kita sudah mengetahui berapa jumlah produk yang akan terjual, maka kita tidak perlu bingung untuk membeli stok untuk penjualan yang akan datang.

Dari permasalahan yang telah dijelaskan maka, maka diperlukan suatu keputusan untuk menemukan strategi yang dapat membantu untuk memprediksi kebutuhan stok barang pada Cv.AGVA Kota Pasuruan. Metode fuzzy time series merupakan salah satu metode yang dapat dicoba untuk memecahkan masalah tersebut menurut jurnal pengembangan aplikasi sebelumnya karena data yang digunakan merupakan data history penjualan alat-alat drumband dibulan sebelumnya. Data histori penjualan yang digunakan merupakan data penjualan dengan masa periode mulai Januari 2016 sampai dengan Desember 2018. Dengan demikian maka pada penelitian ini mengambil judul "Penerapan Metode Fuzzy Time Series Untuk Prediksi Penjualan Berbasis Web pada Cv.AGVA Kota Pasuruan”.

\subsection{Rumusan Masalah}

Mengacu pada permasalahan, maka dapat dirumuskan masalah sebagai berikut:

1. Bagaimana membuat sistem peralaman pada Cv.AGVA?

2. Bagaimana menghitung jumlah penjualan optimal pada Cv.AGVA ?

3. Bagaimana peramalan kebutuhan pada Cv.AGVA pada periode-periode berikutnya?

\subsection{Tujuan}

Adapun tujuan dari pengembangan aplikasi ini adalah :

1. Menghitung hasil prediksi agar mendapatkan hasil yang lebih tepat dan akurat.

2. Peramalan pada Cv.AGVA dilakukan menggunakan metode Fuzzy Time Series.

3. Membuat sistem berbasis Web menggunakan bahasa pemrograman PHP, CSS, JavaScript. 


\subsection{Batasan Masalah}

Agar tidak terjadi penyimpangan, maksud dan tujuan utama penyusunan skripsi ini maka perlu diberikan batasan masalah, antara lain :

1. Data yang digunakan dalam pembuatan sistem prediksi penjualan pada Cv.AGVA adalah data pada tahun 2016 - 2018.

2. Target pengguna hanya ditujukan untuk Admin dan Pemilik Cv.AGVA.

3. Bahasa pemograman yang yang digunakan dalam proses pembuatan yaitu PHP, CSS, JavaScript.

4. Metode yang digunakan adalah Fuzzy Time Series.

\section{TINJAUAN PUSTAKA}

\subsection{Penelitian Terkait Peramalan Penjualan}

Berdasarkan teori dan metode penelitian yang berhubungan dengan prediksi menggunakan metode fuzzy time series yang penulis buat untuk di jadikan sebagai bahan masukan guna ketepatan pelaksanaan sistem dapat di uraikan sebagai berikut :

Menurut penelitian yang dilakukan oleh Ekananta dkk, dalam penelitiannya yang berjudul "Penerapan Metode Average-Based Fuzzy Time Series Untuk Prediksi Konsumsi Energi Listrik Indonesia" pada tahun 2015, Data jumlah konsumsi energi listrik dipilih karena memiliki karakteristik yang tepat yaitu termasuk dalam golongan data trend. Pada bagian pengujian yang dilakukan menggunakan keseluruhan data dengan menggunakan metode fuzzy time series menghasilkan nilai MAPE $=14,27 \%$. Hasil tersebut termasuk kriteria baik (Ekananta dkk, 2015).

Menurut penelitian yang dilakukan oleh Uliana pada tahun 2017 yang berjudul "Penerapan Metode Average-Based Fuzzy Time Series dengan Pergerakan Data Harga Saham Minyak". Penyelesaian dengan menggunakan data fuzzy time series panjang interval telah ditentukan di awal proses perhitungan, proses ini sangat berpengaruh dalam pembentukan fuzzy relationship yang tentu akan memberikan dampak perbedaan hasil perhitungan peramalan. Hasil pengujian yang diketahui bahwa peramalan data menggunakan fuzzy time series dengan penentuan panjang interval berbasis rata-rata di dapatkan nilai MAPE $1.2559969 \%$ (Uliana, 2017).

Selanjutnya Elfajar dkk pada tahun 2017 telah melakukan penelitian yang berjudul "Peramalan Jumlah Kunjungan Wisatawan Kota Batu Menggunakan Metode Time Invariant Fuzzy Time Series". Metode fuzzy time series di implementasikan untuk meramalkan data pengunjung bulanan, adapun data yang digunakan untuk pengujian adalah data yang berasal dari Dinas Pariwisata Kota Batu dan dari hasil pengujian yang dilakukan, diketahui bahwa peramalan menggunakan fuzzy set berbasis rata - rata didapatkan nilai rata - rata error average forecasting error rate (AFER) terbaik sebesar $0,0056 \%$ dengan menggunakan 60 data latih (Elfajar dkk, 2017).

Menurut penelitian. Yang dilakukan Ardinansyah pada tahun 2018, yang berjudul "Implementasi Metode Fuzzy Time Series Untuk Prediksi Kebutuhan Bahan Baku Pokok Produk Makanan Pada Kedai Dampizza". Tingkat permintaan konsumen terhadap suatu produk makanan yang berubah-ubah setiap bulanya. Tingkat permintaan konsumen terhadap suatu produk yang sering berubah-ubah dapat mempengaruhi persediaan bahan baku pokok yang dipergunakan untuk membuat suatu produk makanan. Pada program digunakan metode fuzzy time series yang menggunakan rumus rata-rata untuk menghitung interval dan himpunan fuzzy. Hasil pengujian program dengan metode fuzzy time series mendapatkan hasil bahwa perhitungan manual dengan sistem memiliki tingkat error atau tingkat kesalahan sebesar 3,83\% (Ardinansyah, 2018).

Menurut penilitan yang dilakukan Saputri pada tahun 2019, yang berjudul "Penerapan metode Fuzzy time series untuk prediksi penjualan berbasis web pada toko grosis 3 roda sengkaling", terjadi permintaan konsumen yang tidak menentu seiring dengan kebutuhan rumah tangga yang makin tinggi. Makin tinggi permintaan konsumen, makin tinggi pula penjualan yang dilakukan oleh toko tersebut. Maka dibuatlah sistem prediksi berbasis web php native menggunakan metode Fuzzy Time Series. Hasil perhitungan akurasi keakuratan metode Fuzzy Time Series berdasarkan data penjualan dari bulan Februari 2017 sampai September 2018 baik melalui simulasi program dan manual. Nilai akurasi keakuratan sebesar 99,3\% (Saputri, 2019).

\subsection{Pengertian prediksi}

Prediksi merupakan bagian awal dari suatu proses pengambilan suatu keputusan. Sebelum melakukan prediksi harus diketahui terlebih dahulu apa sebenarnya persoalan dalam pengambilan keputusan itu. Prediksi adalah ilmu untuk memperkirakan kejadian dimasa depan. Hal tersebut dapat dilakukan dengan pengambilan data historis atau data-data masa lalu dan memproyeksikan ke masa mendatang dengan suatu bentuk model matematis. Pada hakekatnya prediksi hanya merupakan suatu perkiraan, tetapi dengan menggunakan teknikteknik tertentu maka prediksi menjadi lebih sekedar perkiraan.

Jangka waktu prediksi dapat dikelompokkan menjadi tiga kategori, sebagai berikut :

1. Prediksi jangka pendek, prediksi untuk jangka waktu kurang dari tiga bulan.

2. Prediksi jangka menengah, prediksi untuk jangka waktu antara tiga bulan sampai tiga tahun.

3. Prediksi jangka panjang, prediksi untuk jangka waktu lebih dari tiga tahun. 


\subsection{Fuzzy Time Series}

Teori himpunan fuzzy Zadeh digunakan untuk mengembangkan model time variant dan time invariant peramalan fuzzy time series dengan menerapkan pada masalah peramalan pendaftaran mahasiswa baru dengan data berkala pada Universitas Alabama (Song dan Chissom, 1993). Beberapa penelitian dan pengembangan metode ini yaitu peramalan dengan metode fuzzy time series pada pendaftaran mahasiswa baru Universitas Alabama menggunakan operasi aritmetika sederhana ( Chen, 1996), Model second order fuzzy time series untuk meramal pendaftaran mahasiswa di Universitas Alabama (Tsai dan Wu, 1999), Menggunakan model high order fuzzy time series untuk mengatasi kelemahan model first order fuzzy time series dengan mengimplementasikan pada peramalan pendaftaran mahasiswa pada Universitas Alabama (Chen, 2002), Model 2 faktor high order fuzzy logical relationship untuk meningkatkan akurasi peramalan (Lee dkk, 2006) selanjutnya metode high order fuzzy time series untuk memprediksi temperatur dan peramalan TAIFEX ( Lee dkk, 2008).

Perbedaan utama antara Fuzzy Time Series dan konvensional time series yaitu pada nilai yang digunakan dalam prediksi, yang merupakan himpunan fuzzy dari bilangan-bilangan real atas himpunan semesta yang ditentukan. Himpunan fuzzy dapat diartikan sebagai suatu kelas bilangan dengan batasan yang samar.

Jika $U$ adalah himpunan semesta $U=\{\mathrm{u} 1, \mathrm{u} 2, \ldots$ , un\}, Maka suatu himpunan fuzzy A dari U didefinisikan sebagai :

$$
\mathrm{A}=f A(u 1) / u 1+f A(u 2) / u 2+\ldots+f A(u n) / u n
$$

Dimana $f A$ adalah fungsi keanggotaan dari A, $f A$ : U $\rightarrow \square[0,1]$ dan $1 \leq \mathrm{i} \leq \mathrm{n}$

Sedangkan definisi dari Fuzzy Time Series adalah misalkan $\mathrm{Y} \quad(\mathrm{t}) \quad(\mathrm{t}=\ldots, 0,1,2, \ldots), \quad$ adalah himpunan bagian dari $\mathrm{R}$, yang menjadi himpunan semesta dimana fuzzy fi(t) $(\mathrm{i}=1,2, \quad \ldots)$ telah didefinisikan sebelumnya dan jadikan $\mathrm{F}(\mathrm{t})$ menjadi kumpulan dari fi(t) $(\mathrm{i}=1,2, \ldots)$. Maka, $\mathrm{F}(\mathrm{t})$ dinyatakan sebagai Fuzzy Time Series terhadap $\mathrm{Y}(\mathrm{t})(\mathrm{t}=\ldots, ., 0,1,2$, ...).

Dari definisi diatas, dapat dilihat bahwa $F(t)$ bisa dianggap sebagai variable linguistik dan fi(t) $(\mathrm{i}=1,2, \ldots)$ bisa dianggap sebagai kemungkinan nilai linguistic dari $\mathrm{F}(\mathrm{t})$, dimana $\mathrm{fi}(\mathrm{t}) \quad(\mathrm{i}=1,2, \ldots)$ direpresentasikan oleh suatu himpunan fuzzy. Bisa dilihat juga bahwa $F(t)$ adalah suatu fungsi waktu dari $\mathrm{t}$ misalnya, nilai-nilai dari $\mathrm{F}(\mathrm{t})$ bisa berbeda pada waktu yang berbeda bergantung pada kenyataan bahwa himpunan semesta bisa berbeda pada waktu yang berbeda. Dan jika $F(t)$ hanya disebabkan oleh $\mathrm{F}(\mathrm{t}-1)$ maka hubungan ini digambarkan sebagai $\mathrm{F}(\mathrm{t}-1)$ $\rightarrow \mathrm{F}(\mathrm{t})$.

Sementara itu, penentuan panjang interval sangat berpengaruh dalam pembentukan fuzzy relationship yang tentunya akan memberikan dampak perbedaan hasil perhitungan prediksi. Oleh karena itu, pembentukan fuzzy relationship haruslah tepat dan hal ini mengharuskan penentuan panjang interval yang sesuai. Kunci utama dalam penentuan panjang interval adalah tidak boleh terlalu besar dan tidak boleh terlalu kecil, karena jika interval itu terlalu besar maka tidak akan terjadi fluktuasi dalam proses perhitungan Fuzzy Time Series, demikian juga jika interval tersebut terlalu kecil maka makna dari Fuzzy Time Series sendiri akan hilang (karena himpunan yang terbentuk cenderung ke himpunan tegas/crisp).

Salah satu metode untuk penentuan panjang interval yang efektif adalah dengan metode berbasis rata-rata (average-based), yang memiliki algoritma sebagaimana berikut [2] :

1. Menghitung semua nilai absolute selisih anatara $\mathrm{Ai}+1$ dan Ai (i=1 ..., n-l) sehingga diperoleh ratarata nilai absolute selisih.

2. Menentukan setengah dari rata-rata yang diperoleh dari langkah pertama untuk kemudian dijadikan sebagai panjang interval.

3. Berdasarkan panjang interval yang diperoleh dari langkah kedua, ditentukan basis dari panjang interval sesuai dengan tabulasi basis pada Tabel 2.1 .

Tabel 2.1. Tabel Basis
\begin{tabular}{|c|c|}
\hline Jangkauan & Basis \\
\hline $0.1-1.0$ & 0.1 \\
\hline $1.1-10$ & 1 \\
\hline $11-100$ & 10 \\
\hline $101-1000$ & 100 \\
\hline
\end{tabular}

4. Panjang interval kemudian dibulatkan sesuai dengan tabel basis interval.

Pada prinsipnya, pengawasan prediksi dilakukan dengan membandingkan hasil prediksi dengan kenyataan yang terjadi. Penggunaan teknik prediksi yang menghasilkan penyimpangan terkecil adalah teknik prediksi yang paling sesuai untuk digunakan.

\subsection{Fuzzy}

Logika fuzzy atau Logika Samar merupakan suatu sistem yang disusun oleh pakar matematika dan komputer yang bernama Lotfi Zadeh. Dalam metode ini, serangkaian bilangan mendapatkan nilai keanggotaan antara 0 dan 1 untuk mengukur suatu keadaan seperti ketinggian, kecantikan, umur dan elemen-elemen lain yang sulit dipastikan. Jadi, di sini kita mempunyai himpunan yang tiap anggotanya mempunyai derajat keanggotaan tertentu . Logika fuzzy adalah suatu cara yang tepat untuk memetakan suatu ruang input ke dalam suatu ruang output.(kusumadewi, 2004)

Ada beberapa hal yang perlu diketahui dalam memahami sistem fuzzy, yaitu: (Sutojo, 2011)

1. Variabel fuzzy merupakan variabel yang hendak dibahas dalam suatu sistem fuzzy.

2. Himpunan fuzzy merupakan suatu grup yang mewakili suatu kondisi atau keadaan tertentu dalam suatu variabel fuzzy. 
Semesta pembicaraan adalah keseluruhan nilai yang diperbolehkan untuk dioperasikan dalam suatu variabel fuzzy. Semesta pembicaraan merupakan himpunan bilangan real yang senantiasa naik (bertambah) secara monoton dari kiri ke kanan. Nilai semesta pembicaraan dapat berupa bilangan positif maupun negatif. Adakalanya nilai semesta pembicaraan ini tidak dibatasi batas atasnya. Domain himpunan fuzzy adalah keseluruhan nilai yang diijinkan dalam semesta pembicaraan dan boleh dioperasikan dalam suatu himpunan fuzzy. Seperti halnya semesta pembicaraan, domain merupakan himpunan bilangan real yang senantiasa naik (bertambah) secara monoton dari kiri ke kanan. Nilai domain dapat bernilai positif maupun negatif.

\section{METODE PENELITIAN}

\subsection{Blok Diagram Sistem}

Dalam system prediksi penjualan yang dikembangkan dalam penelitian ini menggunakan metode Fuzzy Time Series yang diaplikasikan pada perhitungan nilai prediksi.

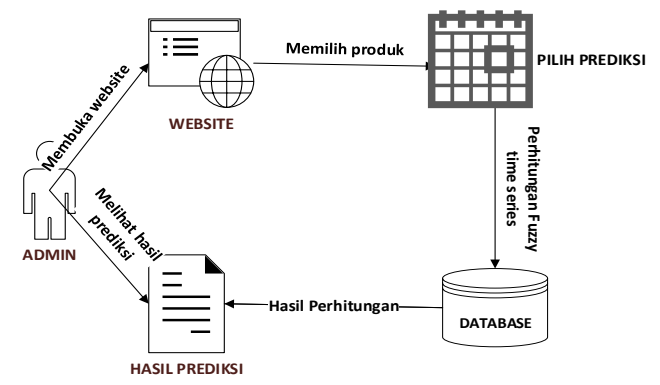

Gambar 1. Blok diagram sistem

Dari blok diagram tersebut menunjukkan bahwa Admin / Pemilik toko membuka browser dan membuka sistem Prediksi Penjualan Pada Cv.AGVA, lalu admin memilih bulan dan tahun yang akan dilakukan perhitungan prediksi penjualan lalu akan ditampilkan hasil prediksi.

\subsection{Flowchart System}

\section{Flowchart Sistem}

Pada sistem ini dimulai dengan user dapat melihat data penjualan dan grafik penjualan. Kemudian admin melakukan input data penjualan dan data barang. Selanjutnya admin bisa melihat hasil perhitungan prediksi penjualan barang per bulan.

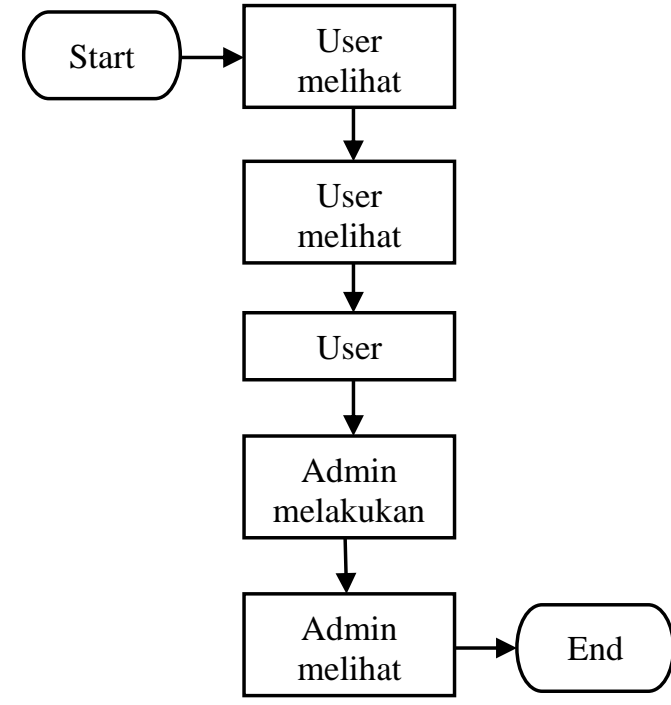

Gambar 2. Flowchart Sistem

2. Flowchart Fuzzy Time Series

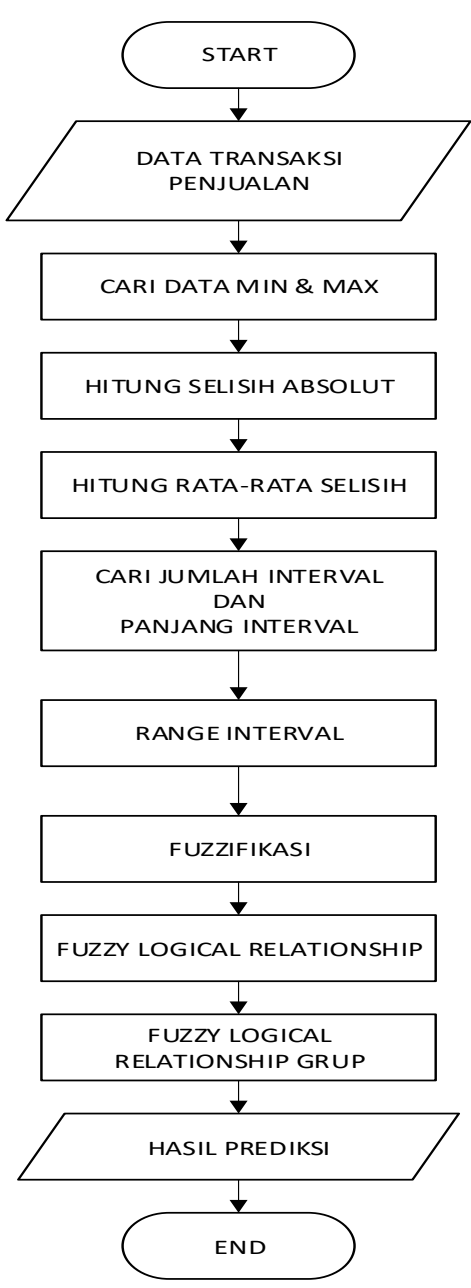

Gambar 3. Flowchart Fuzzy Time Series 
Langkah 1. Memasukkan data yang akan diprediksi dengan metode Fuzzy Time Series. Data aktual penjualan Marching Bell dari bulan JanuariDesember 2016.

Tabel 3.1 Tabel data penjualan

\begin{tabular}{|c|c|c|c|c|c|}
\hline Tahun & Bulan & Qty & Tahun & Bulan & Qty \\
\hline 2016 & Januari & 30 & 2016 & Juli & 23 \\
\hline 2016 & Februari & 30 & 2016 & Agustus & 24 \\
\hline 2016 & Maret & 20 & 2016 & September & 28 \\
\hline 2016 & April & 26 & 2016 & Oktober & 30 \\
\hline 2016 & Mei & 31 & 2016 & November & 38 \\
\hline 2016 & Juni & 25 & 2016 & Desember & 28 \\
\hline
\end{tabular}

Langkah 2. Membagi himpunan semesta $U=$ [Dmin,Dmax] menjadi sejumlah interval yaitu $\mathrm{u} 1, \mathrm{u} 2, \ldots$, um, menggunakan metode berbasis rata-rata dengan penerapan algoritma sebagai berikut :

1. Mencari selisih absolute antar data time series diperoleh nilai $0,10,6,5,6,2,1,4,2,8,10$ Maka bisa diketahui bahwa rata - rata data selisih adalah 4,90.

2. Jika nilai 4,90 dibagi dua maka diperoleh nilai 2,45 yang jika dirujuk pada table inerval maka basis interval yang digunakan yaitu 1 .

3. Kemudian nilai 2,45 dibulatkan berdasarkan basis sehingga diperoleh nilai 1 sebagai panjang interval efektif.

Tabel 3.2 Tabel interval

\begin{tabular}{|c|c|}
\hline Jangkauan & Basis \\
\hline $0.1-1.0$ & 0.1 \\
\hline $1.1-10$ & 1 \\
\hline $11-100$ & 10 \\
\hline $101-1000$ & 100 \\
\hline
\end{tabular}

Dan Jika 1 digunakan sebagai panjang interval untuk membagi himpunan semesta (U), maka jumlah interval dapat diperoleh dari hasil bagi jangkauan interval, 38 (nilai maksimum) dikurangi 20 (nilai minimum) adalah 18 . Kemudian 18 dibagi 1 diperoleh nilai 18 .

Tabel 3.3 Tabel range interval

\begin{tabular}{|l|l|}
\hline $\mathrm{U} 1=[20,21]$ & $\mathrm{U} 10=[29.1,30]$ \\
\hline $\mathrm{U} 2=[21.1,22]$ & $\mathrm{U} 11=[30.1,31]$ \\
\hline $\mathrm{U} 3=[22.1,23]$ & $\mathrm{U} 12=[31.1,32]$ \\
\hline $\mathrm{U} 4=[23.1,24]$ & $\mathrm{U} 13=[32.1,33]$ \\
\hline $\mathrm{U} 5=[24.1,25]$ & $\mathrm{U} 14=[33.1,34]$ \\
\hline $\mathrm{U} 6=[25.1,26]$ & $\mathrm{U} 15=[34.1,35]$ \\
\hline $\mathrm{U} 7=[26.1,27]$ & $\mathrm{U} 16=[35.1,36]$ \\
\hline $\mathrm{U} 8=[27.1,28]$ & $\mathrm{U} 17=[36.1,37]$ \\
\hline $\mathrm{U} 9=[28.1,29]$ & $\mathrm{U} 18=[37.1,38]$ \\
\hline
\end{tabular}

Langkah 3. Terbentuklah A1, A2, ..., Ak menjadi suatu himpunan fuzzy yang variabel linguistiknya ditentukan sesuai dengan keadaan semesta. Himpunan fuzzy $\mathrm{Ai}$ menunjukkan derajat keanggotaan dari uj. Adapun data aktual yang telah di fuzzifikasi.

Tabel 3.4 Tabel fuzzifikasi

\begin{tabular}{|c|c|c|c|}
\hline \multirow{2}{*}{ Tahun } & \multirow{2}{*}{ Bulan } & Terjual & Fuzzif \\
\cline { 3 - 4 } & & Marching Bell & ikasi \\
\hline \multirow{7}{*}{} & Januari & 30 & $\mathrm{~A} 10$ \\
\cline { 2 - 4 } & Februari & 30 & $\mathrm{~A} 10$ \\
\cline { 2 - 4 } & Maret & 20 & $\mathrm{~A} 1$ \\
\cline { 2 - 4 } & April & 26 & $\mathrm{~A} 6$ \\
\cline { 2 - 4 } & Mei & 31 & $\mathrm{~A} 11$ \\
\cline { 2 - 4 } & Juni & 25 & $\mathrm{~A} 5$ \\
\cline { 2 - 4 } & Juli & 23 & $\mathrm{~A} 3$ \\
\cline { 2 - 4 } & Agustus & 24 & $\mathrm{~A} 4$ \\
\cline { 2 - 4 } & September & 28 & $\mathrm{~A} 8$ \\
\cline { 2 - 4 } & Oktober & 30 & $\mathrm{~A} 10$ \\
\cline { 2 - 4 } & November & 38 & $\mathrm{~A} 18$ \\
\cline { 2 - 4 } & Desember & 28 & $\mathrm{~A} 8$ \\
\hline
\end{tabular}

Langkah 4. Menentukan fuzzy logical relationship. Dari tabel 3.4 maka bisa diperoleh fuzzy logical relationship $\mathrm{Aj} \rightarrow \mathrm{Ak}$ berarti jika nilai enrollment pada tahun $\mathrm{i}$ adalah $\mathrm{Aj}$ maka pada tahun $\mathrm{i}+1$ adalah Ak. Aj sebagai sisi kiri relationship disebut current state dan Ak sebagai sisi kanan relationship disebut sebagai next state. Dan jika terjadi perulangan hubungan maka tetap dihitung sekali. Adapun tabel fuzzy logical relationship.

Tabel 3.5 Tabel fuzzy logical relation

\begin{tabular}{|l|l|l|}
\hline \multicolumn{3}{|c|}{ Fuzzy Logical Relationship } \\
\hline A10 -> A10 & A11 -> A5 & A8 -> A10 \\
\hline A10 -> A1 & A5 -> A3 & A10 -> A18 \\
\hline A1 -> A6 & A3 -> A4 & A18 -> A8 \\
\hline A6 -> A11 & A4 -> A8 & \\
\hline
\end{tabular}

Langkah 5. Membagi fuzzy logical relationship yang telah diperoleh menjadi beberapa bagian berdasarkan sisi kiri (current state). Sebagaimana kita peroleh tujuh fuzzy logical relationship group.

Tabel 3.6 Tabel Fuzzy relation group
\begin{tabular}{|l|l|}
\hline Fuzzy Logical Relation Group \\
\hline G1 & A 1 -> A6 \\
\hline G2 & A 3 -> A4 \\
\hline G3 & A4 -> A8 \\
\hline G4 & A5 ->A3 \\
\hline G5 & A6 -> A 11 \\
\hline G6 & A8 -> A10 \\
\hline G7 & A10 ->A1,A10,A18 \\
\hline G8 & A11 -> A5 \\
\hline G9 & A18 -> A8 \\
\hline
\end{tabular}

Langkah 6. Melakukan perhitungan prediksi atau defuzzifikasi berdasarkan FLRG yang telah dibentuk. 
Tabel 3.7 Tabel defuzzifikasi

\begin{tabular}{|l|l|c|}
\hline \multicolumn{2}{|c|}{ Fuzzy logic relationship groups } & Defuzzifikasi \\
\hline G1 & A1 - A6 & 25,55 \\
\hline G2 & A3 - A4 & 23,55 \\
\hline G3 & A4 -> A8 & 27,55 \\
\hline G4 & A5 -> A3 & 22,55 \\
\hline G5 & A6 -> A11 & 30,55 \\
\hline G6 & A8 -> A10 & 29,55 \\
\hline G7 & A10 -> A1,A10,A18 & 29,2 \\
\hline G8 & A11 -> A5 & 24,55 \\
\hline G9 & A18 -> A8 & 27,55 \\
\hline
\end{tabular}

Berdasarkan hasil defuzzifikasi tiap grup maka dilakukan proses prediksi untuk tiap data yang ada.

Tabel 3.8 Tabel hasil prediksi

\begin{tabular}{|c|c|c|c|c|}
\hline \multirow{2}{*}{ Tahun } & \multirow{2}{*}{ Bulan } & Terjual & Fuzzi & Defuzz \\
& & Marching & fikasi & ifikasi \\
\hline \multirow{7}{*}{} & Januari & 30 & A10 & - \\
\cline { 2 - 5 } & Februari & 30 & A10 & 29 \\
\cline { 2 - 5 } & Maret & 20 & A1 & 26 \\
\cline { 2 - 5 } & April & 26 & A6 & 31 \\
\cline { 2 - 5 } & Mei & 31 & A11 & 25 \\
\cline { 2 - 5 } & Juni & 25 & A5 & 23 \\
\cline { 2 - 5 } & Juli & 23 & A3 & 24 \\
\cline { 2 - 5 } & Agustus & 24 & A4 & 28 \\
\cline { 2 - 5 } & September & 28 & A8 & 30 \\
\cline { 2 - 5 } & Oktober & 30 & A10 & 29 \\
\cline { 2 - 5 } & November & 38 & A18 & 28 \\
\cline { 2 - 5 } & Desember & 28 & A8 & 30 \\
\hline
\end{tabular}

3.3. Struktur Menu

1. Dalam system prediksi penjualan yang dikembangkan dalam penelitian ini menggunakan metode Fuzzy Time Series yang diaplikasikan pada perhitungan nilai prediksi.

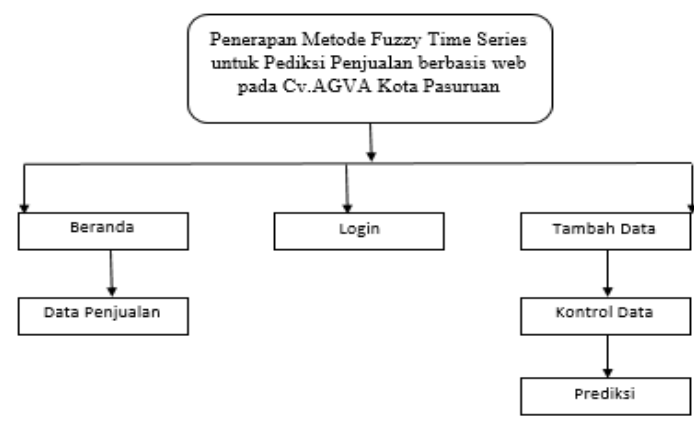

Gambar 4. Struktur Menu

\section{HASIL DAN PEMBAHASAN}

\subsection{Implementasi}

Tahap implementasi merupakan tahapan penerapan rancangan aplikasi ke dalam bentuk nyata, yaitu berupa aplikasi yang berjalan pada platform web. Berikut tampilan hasil yang ada pada sistem.

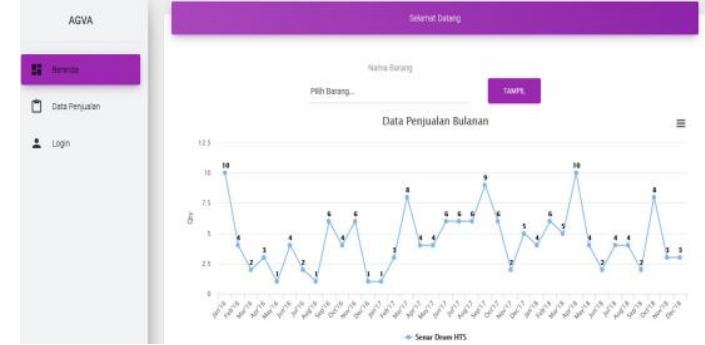

Gambar 5. Halaman beranda user

Halaman awal dari aplikasi ini merupakan tampilan halaman grafik data penjualan barang. Pada tampilan awal aplikasi ini dijelaskan seperti pada Gambar 5.

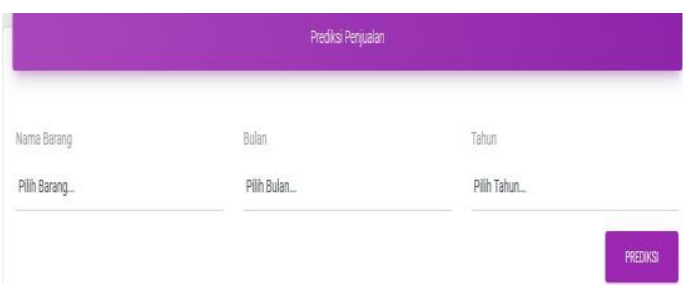

Gambar 10. Halaman Prediksi Penjualan

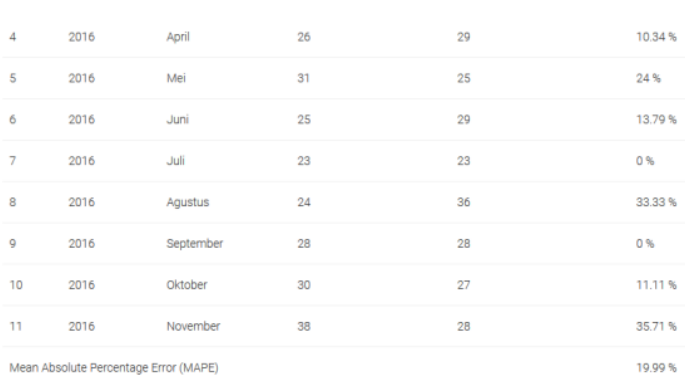

Gambar 11. Halaman Prediksi Penjualan

Pada halaman prediksi penjualan ini digunakan untuk memprediksi penjualan barang berdasarkan nama barang, bulan dan tahun yang akan diprediksi. Adapun halaman prediksi penjualan seperti dijelaskan pada Gambar 10.

\subsection{Pengujian}

1. Pengujian Fungsionalitas Menu Website

Pada tahap pengujian aplikasi dilakukan dengan menggunakan 2 browser yaitu Google Chrome 70.0.3 (GC) dan Mozilla Firefox 61.0.2. (MF) Pengujian ini dilakukan untuk mengetahui fungsional aplikasi berbasis web. Hasil pengujian ditunjukkan pada Tabel 4.1.

Tabel 4.1. Tabel Pengujian Browser

\begin{tabular}{|c|l|c|l|}
\hline $\begin{array}{c}\text { Hak } \\
\text { Akses }\end{array}$ & \multicolumn{1}{|c|}{ Fungsi } & GC & MF \\
\hline User & Halaman Beranda & $\checkmark$ & $\checkmark$ \\
\hline & Grafik Data Penjualan & $\checkmark$ & $\checkmark$ \\
\hline & Tombol Tampil Grafik & $\checkmark$ & $\checkmark$ \\
\hline & Halaman Login & $\checkmark$ & $\checkmark$ \\
\hline & Tombol Login & $\checkmark$ & $\checkmark$ \\
\hline Admin & Halaman Beranda & $\checkmark$ & $\checkmark$ \\
\hline & Halaman Input Data & $\checkmark$ & $\checkmark$ \\
\hline
\end{tabular}




\begin{tabular}{|c|l|c|c|}
\hline & Halaman Kontrol Data & $\checkmark$ & $\checkmark$ \\
\hline & Halaman Detail Data & $\checkmark$ & $\checkmark$ \\
\hline & Halaman Edit Data & $\checkmark$ & $\checkmark$ \\
\hline & Halaman Prediksi Penjualan & $\checkmark$ & $\checkmark$ \\
\hline & Tombol Input Data & $\checkmark$ & $\checkmark$ \\
\hline & Tombol Detail Data & $\checkmark$ & $\checkmark$ \\
\hline & Tombol Edit Data & $\checkmark$ & $\checkmark$ \\
\hline & Tombol Prediksi Penjualan & $\checkmark$ & $\checkmark$ \\
\hline$\checkmark:$ Aplikasi Dapat \\
$\quad \begin{array}{l}\text { Dijalankan } \\
\times:\end{array}$ \\
Aplikasi Tidak Dapat \\
Dijalankan
\end{tabular}

\section{KESIMPULAN DAN SARAN}

\subsection{Kesimpulan}

Berdasarkan hasil analisa dan pengujian yang telah dilakukan, maka dapat diambil beberapa kesimpulan sebagai berikut:

1. Perhitungan prediksi penjualan sudah sesuai dengan perhitungan metode yang digunakan.

2. Dari hasil presentase MAPE pada sistem didapatkan nilai sebesar 2,28\% untuk prediksi penjualan Marching Bell.

\subsection{Saran}

Adapun saran yang diberikan untuk penelitian selanjutnya antara lain:

1. Dikembangkan dalam penelitian selanjutnya agar dapat memungkinkan untuk prosentase selisih prediksi agar lebih kecil lagi.

2. Dikembangkan untuk dapat memprediksi penjualan barang berdasarkan tahun.

\section{DAFTAR PUSTAKA}

[1] Alfian Nurlifa, S. K. (2017). Sistem Peramalan Jumlah Penjualan Menggunakan Metode Moving Average Pada Rumah Jilbab Zaky. Sistem Peramalan Jumlah Penjualan.

[2] Djie, I. S. (t.thn.). Analisis Peramalan Penjualan Dan Penggunaan Metode Linear Programming Dan Decision Tree Guna Mengoptimalkan Keuntungan Pada Pt Primajaya Pantes Garment. Analisis Peramalan Penjualan.

[3] Henny Yulius, Y. P. (t.thn.). Peramalan Penjualan Pada Usaha Kecil Menengah (Ukm) Roti Sania Dengan Menggunakan Program Pom Qm. Peramalan Penjualan Pada UKM.

[4] Puspa Linda, M. S. (2014). Peramalan Penjualan Produksi Teh Botol Sosro Pada Pt. Sinar Sosro Sumatera Bagian Utara Tahun 2014 Dengan Metode Arima Box-Jenkins. Peramalan Penjualan Produksi.
[5] Retno Putri Lestari, M. (t.thn.). Peramalan Produksi Roti Menggunakan Metode Trend Musiman (Studi Kasus Pabrik Roti Mr.Bread Bantargebang, Bekasi). Peramalan Produksi Roti.

[6] Siti Wardah, I. (2016). Analisis Peramalan Penjualan Produk Keripik Pisang Kemasan Bungkus (Studi Kasus : Home Industry Arwana Food Tembilahan). Analisis Peramalan Penjualan Produk.

[7] Edy purnomo, (2018). Penerapan Metode Trend Moment Untuk Forecast Penjualan Barang Di Indomaret (Studi kasus : Gerai Toko Indomaret di Kalimantan Timur). Penerapan Forecast barang.

[8] M Syauqi. Implementasi Metode Fuzzy Time Series Dengan Penentuan Interval Berbasis Rata - Rata Untuk Peramalan Data Penjualan Bulanan. Universitas Brawijaya malang.

[9] Kustiyahningsih, D. Rosa, Pemrograman Basis Data Berbasis Web Menggunakan PHP Dan Mysql, Yogyakarta: Graha Ilmu, 2011.

[10] Firman, astria. 2016. Sistem Informasi Perpustakaan Online Berbasis Web. E Journal Teknik Elektro Dan Komputer. 5(2):29-36I.

[11] Yulius, henny. 2017. Peramalan Penjualan Pada Usaha Kecil Menengah (Ukm) Roti Sania Dengan Menggunakan Program POM QM. Jurnal Edik informatka. 6(1):64:69.

[12] Kusumadewi, S \& Purnomo, H 2004, Aplikasi Logika Fuzzy Untuk Pendukung Keputusan, Graha Ilmu, Yogyakarta.

[13] Sutojo, Mulyanto, \& Suhartono, V. (2011). Kecerdasan Buatan. Yogyakarta: Andi Offset.

[14] Yudi. 2018. Peramalan Penjualan Mesin Industri Rumah Tangga Denganmetode Fuzzy Time Series Ruey CHYN TSAUR. Jurnal Informatika Kaputana (JIK).2(1):52-59.

[15] Nugroho, Kristiawan. 2012. Model Analisis Prediksi Menggunakan Metode Fuzzy Time Series. 1(16):46:50.

[16] Ningsih, Nurlia. 2017. Penerapan Metode Fuzzy Mamdani Untuk Memprediksi Penjualan Gula. Seminar Matematika Dan Pendidikan Matematika Uny. ISBN. 978-602-73403-2-9.

[17] Saputri, F. and Ayuni, R., 2019. Penerapan Metode Fuzzy Time Series Untuk Prediksi Penjualan Berbasis Web Pada Toko Grosir 3 Roda Sengkaling (Doctoral dissertation, Institut Teknologi Nasional Malang). 